\title{
Caracterización mecánica de aleaciones Ti-Nb mediante ensayos de flexión biaxial
}

\author{
E. Benavente-Martínez*, F. Devesa** y V. Amigó**
}

\begin{abstract}
Resumen
En la actualidad, cada vez, son más importantes en la industria las aleaciones de titanio. En especial las aleaciones tipo- $\beta$, que destacan por tener buenas propiedades resistentes y bajos módulos elásticos, en comparación con el Ti c.p. o el Ti-6Al-4V. Dentro de estas aleaciones cabe destacar las Ti-Nb con altos contenidos en elementos aleantes. En este trabajo se han obtenido, mediante pulvimetalurgia convencional, una serie de aleaciones $\mathrm{Ti}-\mathrm{Nb}$, en el rango del $20-40 \%$ de niobio. Se ha obtenido la evolución de las propiedades de dichas aleaciones en función del porcentaje de niobio, mediante la utilización del ensayo de flexión biaxial con tres apoyos (three ball test).
\end{abstract}

\section{Mechanical characterization of Ti-Nb alloys by ball on three balls test}

\begin{abstract}
Nowadays titanium and titanium alloys are increasingly being used in the industry. Particularly $\beta$-Ti alloys that stand out for having great strength properties and low elastic modulus compared to Ti c.p. or Ti-6Al-4V. Among Ti alloys, $\mathrm{Ti}-\mathrm{Nb}$ alloys with high contents of alloying elements are widely used. In this work Ti-Nb alloys have been obtained using conventional powder metallurgy. It has been studied the evolution of properties of these alloys as a function of the percentage of niobium. It can be noted the ball on three balls test used in order to characterize the samples.
\end{abstract}

Keywords

Powder metallurgy; Ti-Nb; Ball on three balls test; Young's modulus; $\beta$-Ti alloys.

\section{INTRODUCCIÓN}

El titanio y sus aleaciones tienen aplicación en diversidad de campos. Uno de los usos más conocidos tiene lugar en el de la biomedicina, por su excelente biocompatibilidad, baja densidad, resistencia a la corrosión y adecuadas propiedades mecánicas ${ }^{[1]}$. También, en otros campos como en el sector automovilístico ${ }^{[2]}$ o, incluso, en el área de equipamiento deportivo ${ }^{[3]}$, está siendo ampliamente utilizado, dado que es un material que destaca por su buena relación resistencia frente a peso.

Las aleaciones de titanio tipo $\beta$ son las más versátiles dentro de las aleaciones de titanio. Destacan por su alta resistencia específica y por la interesante combinación de resistencia, tenacidad y resistencia a la fatiga. Además, por su bajo módulo elástico y buena resistencia a la corrosión constituyen un material muy apropiado para implantes quirúrgicos ${ }^{[4}$ y 5$]$.
Por esta razón es de especial interés el estudio de aleaciones base titanio a partir de elementos no tóxicos como niobio, molibdeno o tántalo, que presentan mejor biocompatibilidad, además de un módulo elástico menor que Ti-6Al-4V por ser estabilizadores de la fase $\beta^{[6 \mathrm{y} 7]}$. La pulvimetalurgia es una técnica que permite obtener formas cercanas a la pieza acabada incluso con geometrías complejas y, dada su versatilidad, es una buena alternativa a la hora de procesar este tipo de aleaciones.

Dentro de la caracterización mecánica, el ensayo de flexión biaxial, ball on three balls, ofrece ventajas respecto a los ensayos uniaxiales, como la fácil preparación de las muestras, la mejor tolerancia a la planitud del disco y la fricción mínima entre la probeta y la bola de carga ${ }^{[8]}$. Es un ensayo típicamente utilizado en materiales frágiles que ha sido aplicado al estudio de la resistencia de las aleaciones $\mathrm{Ti}-\mathrm{Nb}$.

\footnotetext{
* Departamento de Metalurgia Física, CENIM, CSIC, Av. Gregorio del Amo 8, 28040 Madrid. e-mail: ebenavente@cenim.csic.es.

** Instituto de Tecnología de Materiales, Universitat Politècnica de València, c/ Vera, s/n, 46022 Valencia. e-mail: vamigo@mcm.upv.es.
} 


\section{TRABAJO EXPERIMENTAL}

La obtención de piezas por vía pulvimetalúrgica incluye dos etapas básicas: en primer lugar, la obtención del polvo y, en segundo, su compactación y sinterización. En este trabajo, los polvos de titanio se obtuvieron por la técnica de HDH y fueron suministrados por Sejong Materials Co. LTD. Los polvos de niobio fueron suministrados por Alfa Aesar. En una primera fase, el polvo de niobio se tamizó para obtener un tamaño de partícula inferior a $25 \mathrm{~mm}$, con el fin de favorecer los procesos de difusión. La aleación se obtuvo por mezcla elemental de polvos y se compactaron $4 \mathrm{~g}$ de material en una prensa uniaxial en frío con una presión de $400 \mathrm{MPa}$, en una matriz cilíndrica de $20 \mathrm{~mm}$ de diámetro, con lo que se obtuvieron pastillas de $4 \mathrm{~mm}$ de espesor aproximado.

Las muestras obtenidas se sometieron a un ciclo térmico de sinterización en un horno Carbolite de alto vacío modelo HVT 15/75/450. El ciclo térmico se caracteriza por un calentamiento desde temperatura ambiente hasta $800{ }^{\circ} \mathrm{C}$ a velocidad de $15^{\circ} \mathrm{C} / \mathrm{min}$. Esta temperatura se mantiene durante 30 min hasta que todas las muestras y el horno alcanzan una temperatura uniforme, con tal de evitar problemas relacionados con gradientes de temperatura y para eliminar posibles restos de lubricante. A continuación, la temperatura se aumenta hasta $1.250^{\circ} \mathrm{C}$, a una velocidad de $10^{\circ} \mathrm{C} / \mathrm{min}$, temperatura en la que se mantiene durante un tiempo de $2 \mathrm{~h}$. Finalmente, se realiza un enfriamiento dentro del horno a una velocidad de $10^{\circ} \mathrm{C} / \mathrm{min}$, hasta alcanzar la temperatura ambiente. Todo este ciclo se ha realizado en condiciones de alto vacío $\left(<10^{-4}\right.$ bar $)$, debido a la gran reactividad que presenta el titanio. Como resultado de este proceso se obtuvo una serie de probetas de la familia $\mathrm{Ti}-\mathrm{xNb}$, donde $\mathrm{x}$ representa el \% de niobio, concretamente, Ti20Nb, Ti25Nb, Ti30Nb, Ti35Nb y $\mathrm{Ti} 40 \mathrm{Nb}$.

La preparación metalográfica fue realizada siguiendo las técnicas convencionales. Posteriormente, las muestras se atacaron con reactivo Kroll ( $3 \mathrm{ml} \mathrm{HF}, 6 \mathrm{ml} \mathrm{HNO} 3,100 \mathrm{ml} \mathrm{H}$ O) para revelar su microestructura. La porosidad y el tamaño de grano medio se midieron mediante técnicas de análisis de imagen. Finalmente, las muestras fueron observadas con un microscopio óptico Nikon Microphot FX y por microscopía electrónica mediante un SEM JEOL JSM 6300.

La microdureza se obtuvo con un microdurómetro Matsuzawa MHT2, con una carga de $300 \mathrm{~g}$ aplicada durante $15 \mathrm{~s}$. Para el ensayo de nanoindentación se utilizó un equipo Nanoindenter G200 de MTS. Se ha usado una punta Berkovich de diamante a carga constante de $300 \mathrm{mN}$. La huella obtenida varía entre $1.500-2.500 \mathrm{~nm}$. Se tomaron los valores de dureza y módulo elástico en el punto de máxima carga. A partir del ensayo de flexión biaxial se obtuvo la tensión máxima soportada por cada aleación. La figura 1 muestra el esquema de dicho ensayo, donde la célula de carga utilizada ha sido de $50 \mathrm{KN}$ y la velocidad de aplicación de carga de $0,5 \mathrm{~mm} / \mathrm{min}$.

\section{RESULTADOS Y DISCUSIÓN}

Centrando el estudio en la caracterización de las muestras en sus diferentes etapas, se han observado bajos valores de densidad relativa, en verde, que atestiguan una baja compresibilidad del polvo. Después del sinterizado, se han alcanzado densidades bastante altas, en torno al $90 \%$, para todas las aleaciones, a pesar de esta baja compresibilidad. Esto, deriva en un alto porcentaje de contracción que se demuestra en la variación dimensional radial sufrida en el sinterizado, alrededor del $10 \%$. Los valores de porosidad son bajos, en todos los casos. En la tabla I se muestran las principales características de las muestras, antes y después de ser sinterizadas.

A partir del ensayo de flexión biaxial se ha obtenido la tensión máxima para cada aleación, utilizando la aproximación propuesta por Timoshenko, recogida por $\mathrm{A}$. Börger ${ }^{[9}$ y 10$]$ :

$$
\sigma_{\max }=\frac{F}{t^{2}}\left\{(1+v)\left[0.485 \ln \left(\frac{R}{t}\right)+0.52\right]+0.48\right\}
$$

siendo, $F$, la fuerza máxima soportada hasta la rotura, $t$ y $R$, el espesor y el radio de la probeta,

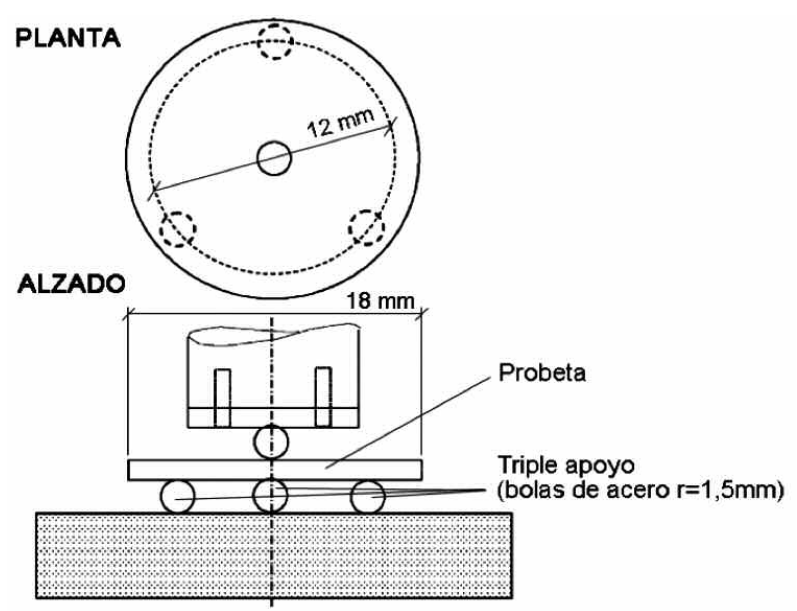

Figura 1. Esquema del montaje para el ensayo de flexión biaxial.

Figure 1. Diagram for ball on three balls test. 
CARACTERIZACIÓN MECÁNICA DE ALEACIONES TI-NB MEDIANTE ENSAYOS DE FLEXIÓN BIAXIAL MECHANICAL CHARACTERIZATION OF TI-NB ALLOYS BY BALL ON THREE BALLS TEST

Tabla I. Caracterización geométrica y dimensional de las aleaciones estudiadas

Table I. Geometric and dimensional characterization of the studied alloys

\begin{tabular}{ccccc}
\hline Aleación & $\begin{array}{c}\text { Variación } \\
\text { dimensional } \\
\text { radial (\%) }\end{array}$ & $\begin{array}{c}\text { Porosidad } \\
\mathbf{( \% )}\end{array}$ & $\begin{array}{c}\text { Densidad } \\
\text { relativa en } \\
\text { verde (\%) }\end{array}$ & $\begin{array}{c}\text { Densidad } \\
\text { relativa } \\
\text { final (\%) }\end{array}$ \\
\hline $\mathrm{Ti}$ & $8,53 \pm 0,16$ & $5,18 \pm 1,16$ & $71,12 \pm 0,49$ & $89,65 \pm 0,56$ \\
$\mathrm{Ti}-20 \mathrm{Nb}$ & $9,74 \pm 0,26$ & $5,83 \pm 1,38$ & $71,26 \pm 0,43$ & $92,90 \pm 1,14$ \\
$\mathrm{Ti}-25 \mathrm{Nb}$ & $8,03 \pm 0,22$ & $6,09 \pm 0,91$ & $69,64 \pm 0,93$ & $88,75 \pm 1,23$ \\
$\mathrm{Ti}-30 \mathrm{Nb}$ & $9,57 \pm 0,21$ & $6,57 \pm 0,52$ & $71,11 \pm 0,05$ & $92,83 \pm 0,18$ \\
$\mathrm{Ti}-35 \mathrm{Nb}$ & $9,03 \pm 0,01$ & $6,60 \pm 0,72$ & $71,45 \pm 0,59$ & $91,55 \pm 0,28$ \\
$\mathrm{Ti}-40 \mathrm{Nb}$ & $8,61 \pm 0,11$ & $6,51 \pm 0,77$ & $70,75 \pm 0,26$ & $89,75 \pm 0,59$ \\
\hline
\end{tabular}

respectivamente y $v$ el coeficiente de Poisson que, para este tipo de aleación, es de 0,34 [11]. En esta ecuación (1) no se tiene en cuenta el módulo elástico. En la tabla II se pueden observar los resultados de dicho ensayo. Cabe destacar que no se han conseguido romper las probetas de Ti c.p. (sin niobio) ya que la deformación elástica en la zona de contacto entre la probeta y los apoyos ha sido excesiva, por lo que la probeta colisiona con el útil de flexión biaxial antes de romper de forma frágil.

Del ensayo de flexión biaxial también se ha obtenido el valor de la pendiente de deformación en la zona elástica de la curva, que se ha definido como rigidez. Dicha rigidez no es, en ningún caso, el módulo elástico pero sirve para comparar las características elásticas de cada aleación. En la figura 2 se representa la disminución de esta rigidez con el mayor contenido en niobio y se observa una mayor disminución con el cambio en la microestructura.

La microestructura de las muestras se han observado mediante microscopia óptica. En la figura 3 se observan los cambios microestructurales en función

Tabla II. Tensión máxima soportada en el ensayo de flexión biaxial

Table II. Maximum stress on ball on three balls test

\begin{tabular}{cc}
\hline Aleación & $\sigma$ max. (MPa) \\
\hline $\mathrm{Ti}$ & - \\
$\mathrm{Ti}-20 \mathrm{Nb}$ & $2.238 \pm 172$ \\
$\mathrm{Ti}-25 \mathrm{Nb}$ & $1.353 \pm 31$ \\
$\mathrm{Ti}-30 \mathrm{Nb}$ & $1.369 \pm 267$ \\
$\mathrm{Ti}-35 \mathrm{Nb}$ & $1.318 \pm 69$ \\
$\mathrm{Ti}-40 \mathrm{Nb}$ & $1.046 \pm 82$ \\
\hline
\end{tabular}

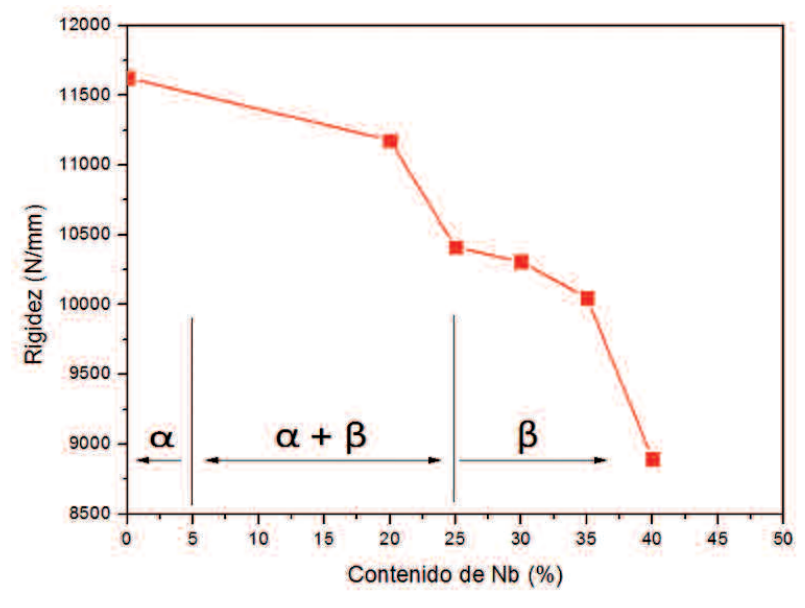

Figura 2. Rigidez de las muestras obtenidas y microestructura en función del contenido en niobio.

Figure 2. Stiffness of the samples and microstructure as a function of niobium content.

del contenido de niobio. En las muestras sin niobio se obtiene una microestructura, tipo $\alpha$, mientras que en las muestras $\mathrm{Ti}-20 \mathrm{Nb}$ y $\mathrm{Ti}-25 \mathrm{Nb}$ se obtiene una microestructura tipo $\alpha+\beta$. Las muestras con 30,35 y $40 \%$ de niobio tienen una microestructura tipo $\beta$, con regiones tipo $\alpha$. En la figura 4 se muestran las imágenes tomadas por microscopía electrónica para las aleaciones tipo $\beta$, donde se aprecia con mayor claridad la estructura $\alpha$ en forma de placas, dispersa en la matriz, que crece, principalmente, a partir de los bordes de grano y subgranos. Además, se aprecia una falta de difusión del niobio en la aleación Ti$40 \mathrm{Nb}$ por el alto contenido de aleante. Es de especial interés la aleación Ti-35Nb, donde sí existe difusión completa a la vez que se obtiene una fase, absolutamente predominante. 

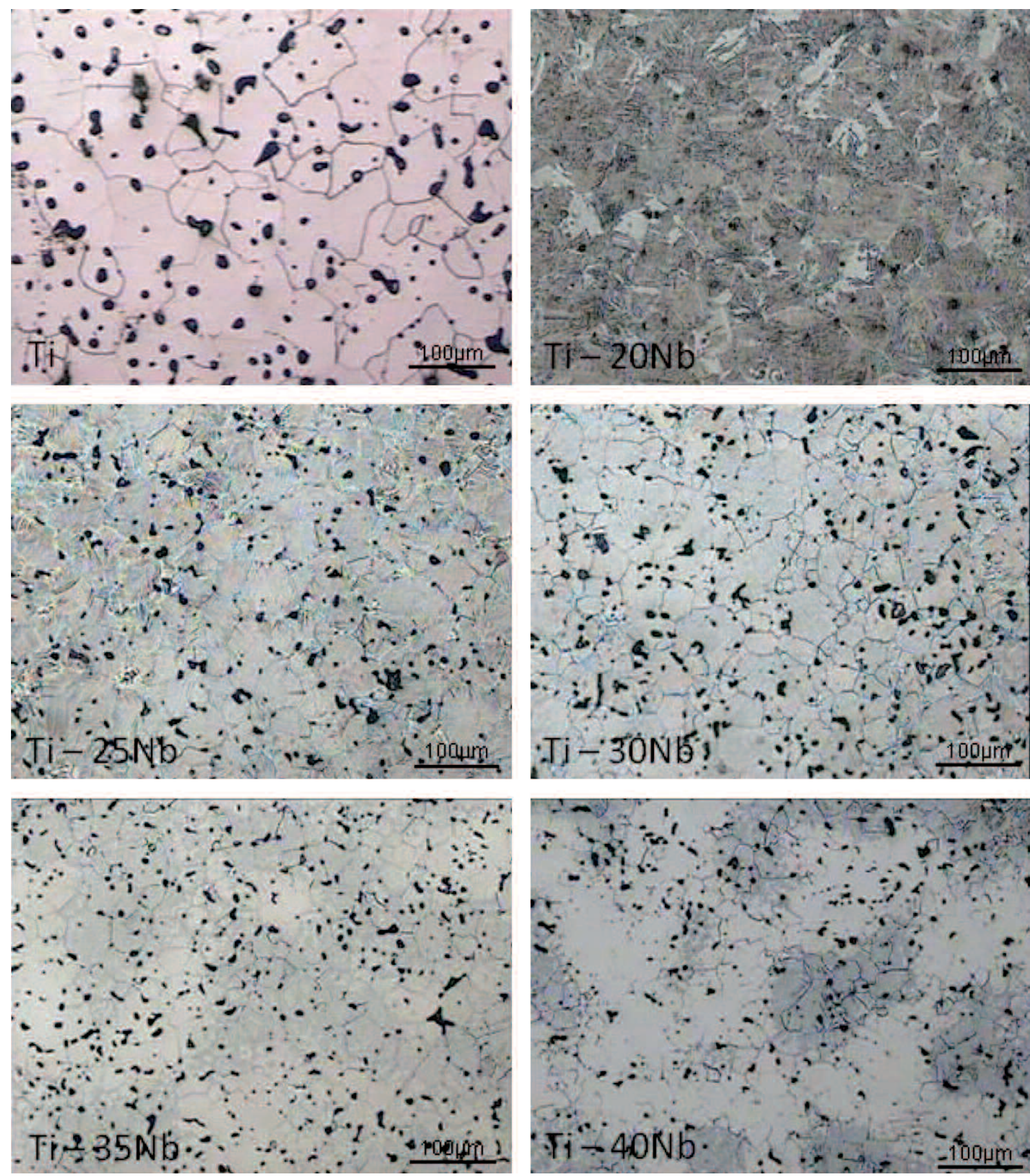

Figura 3. Microestructura de las aleaciones estudiadas obtenidas por microscopia óptica.

Figure 3. Microstructure of the studied alloys obtained by optical microscopy.

De los resultados del ensayo de flexión biaxial, tambié se han obtenido imágenes de las fracturas. En estas imágenes se observa que todas las probetas que han roto muestran el mismo tipo de fractura frágil. Se aprecian cambios en la penetración de los apoyos en las muestras. Cuanto menor es el contenido de elemento aleante mayor es la penetración de la bola en la muestra. Esto es lógico ya que la tensión máxima antes de la rotura es, también, mayor y la recuperación elástica del material es, cada vez, menor. En la figura 5 se muestran las imágenes de la fractura tomadas mediante microscopía estereoscópica.

Continuando con la caracterización mecánica de las aleaciones se han tomado valores de la microdureza. Se ha obtenido una disminución de la microdureza cuanto mayor es el contenido de niobio. Por 

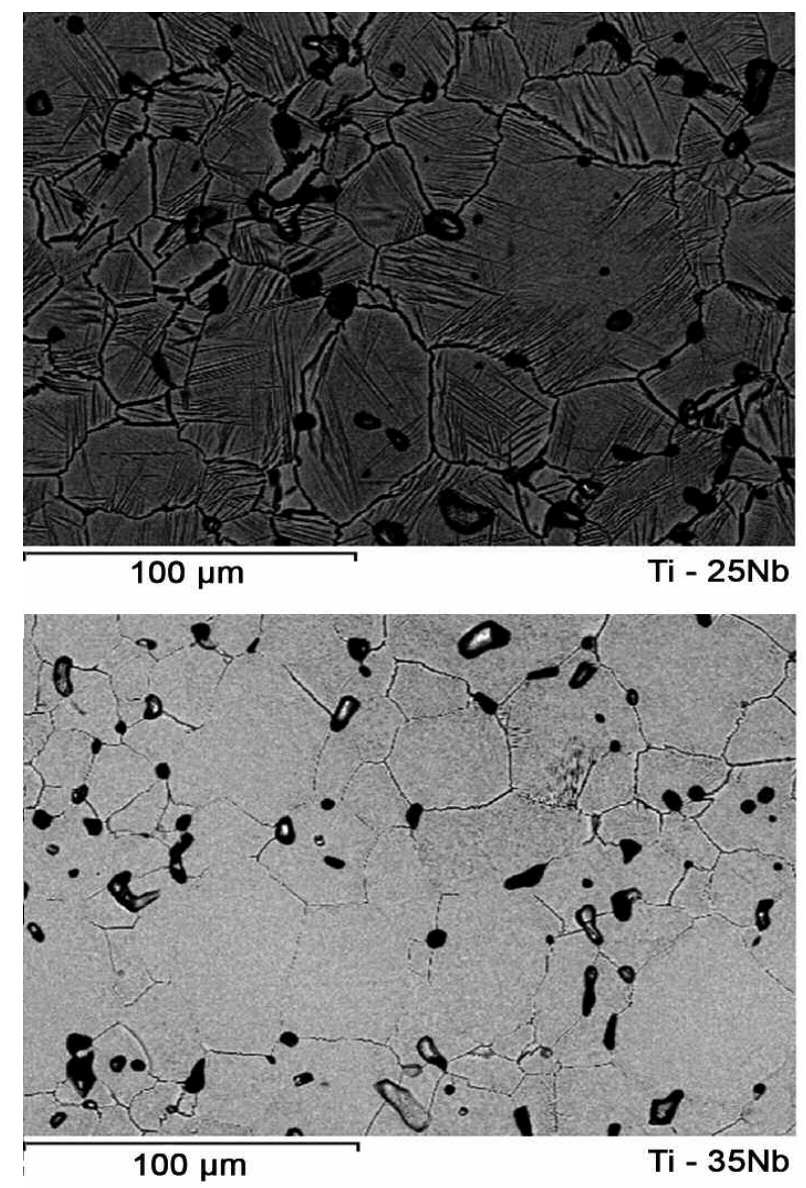
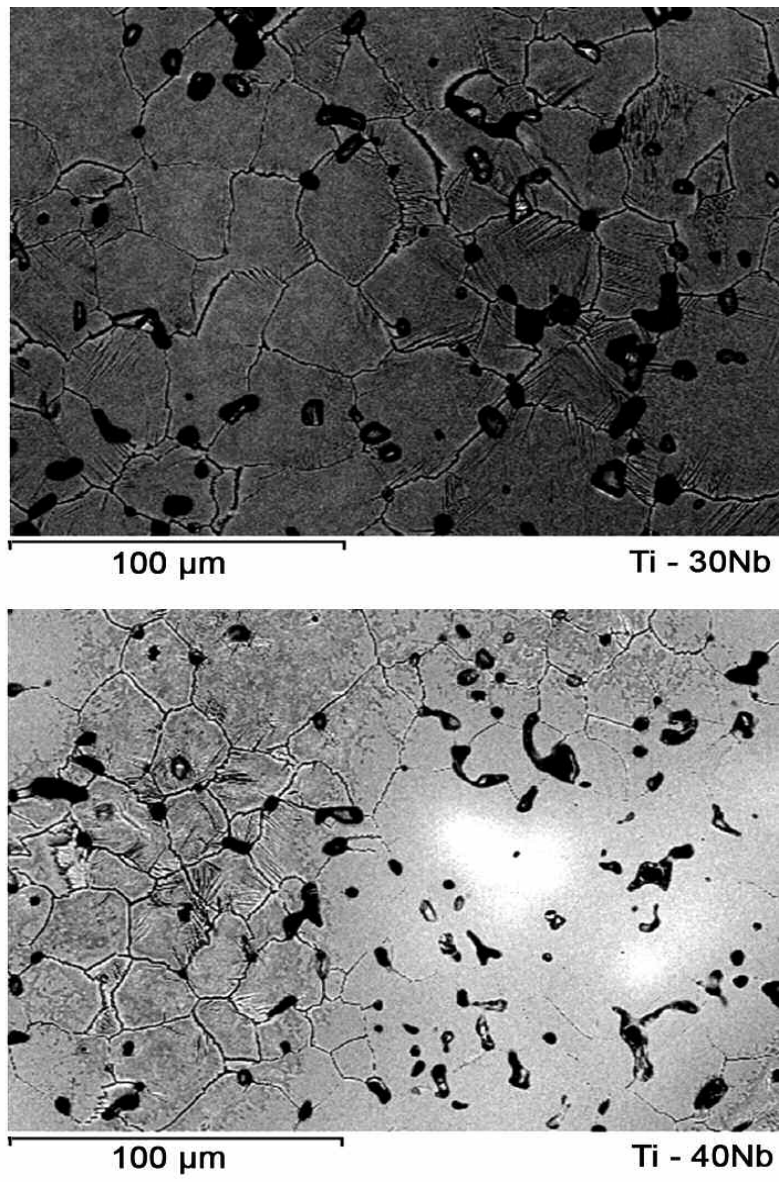

Figura 4. Microestructura de las aleaciones, tipo $\beta$, obtenidas por microscopia electrónica.

Figure 4. Microstructure of $\beta$-Ti Alloys obtained by SEM.
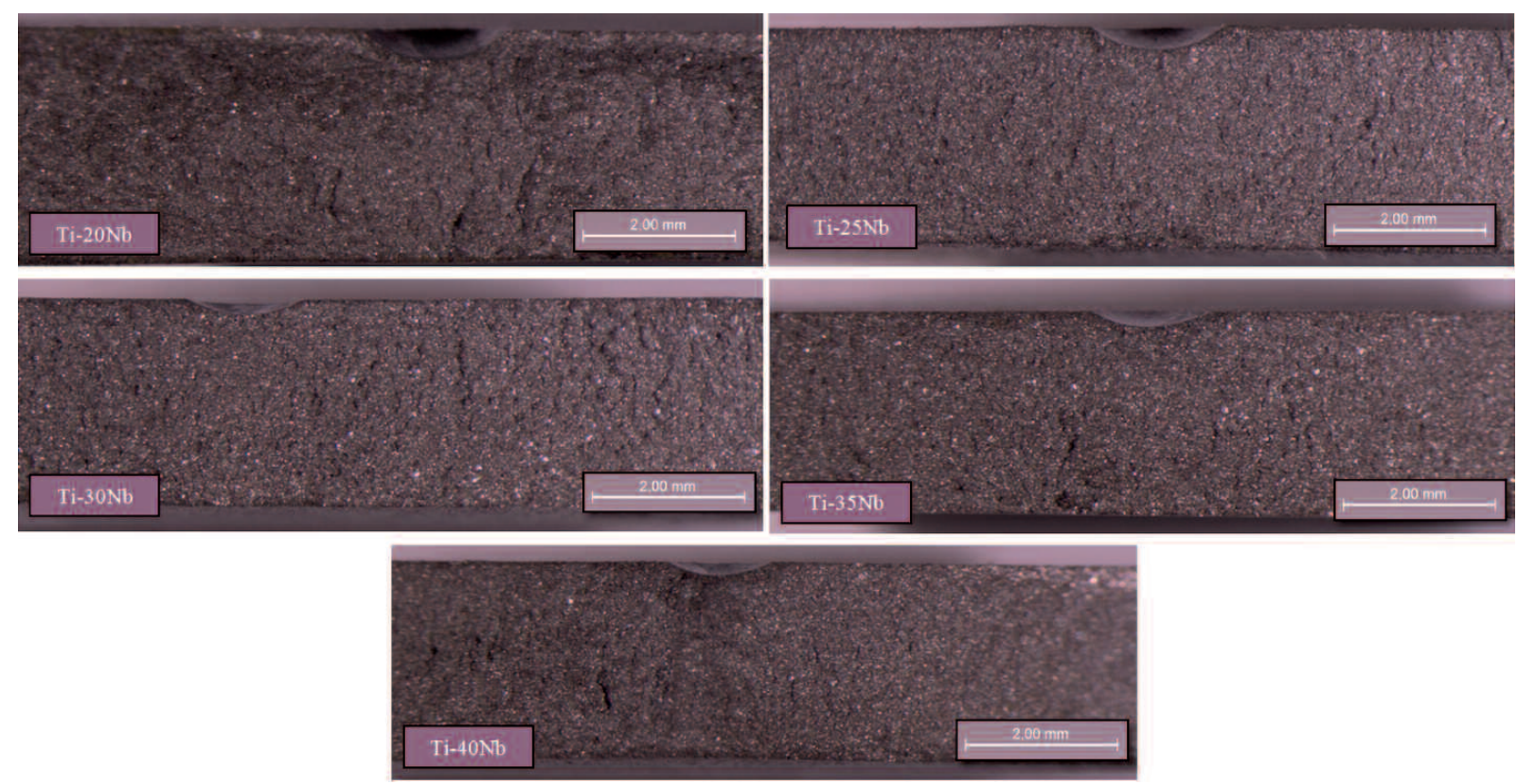

Figura 5. Zona central de la fractura de las muestras.

Figure 5. Central area of the fracture of the samples. 
otro lado, también se ha medido el tamaño de grano y se observa una disminución en función del mayor contenido en elemento aleante, lo que demuestra que el niobio actúa como afinador de grano.

Estos datos pueden llevar a error, ya que la microdureza debería ser mayor cuanto menor es el tamaño de grano pero, en este caso, el efecto contrario de los elementos aleantes es mucho más fuerte que el del tamaño de grano. En la tabla III se observan los resultados de microdureza y tamaño de grano para todos las materiales estudiados.

Por último y dado la gran relevancia que están tomando las aleaciones de titanio, tipo $\beta$, se han obtenido los valores de nanodureza y modulo elástico mediante el ensayo de nanoindentación de las muestras con este tipo de estructura $(\mathrm{Ti}-30 \mathrm{Nb}, \mathrm{Ti}-35 \mathrm{Nb}$ y $\mathrm{Ti}-40 \mathrm{Nb}$ ). Los resultados de nanodureza y microdureza siguen la misma evolución aunque los valores absolutos no coinciden, dada la gran diferencia entre ambas técnicas. A la hora de obtener las medidas, en el ensayo de microdureza se mide la huella dejada por la indentación después de descargar y, por tanto, después de la recuperación elástica, mientras que en el ensayo de nanoindentación se obtiene el valor de dureza en el instante de máxima penetración del indentador, por lo que sí que se tiene en cuenta la deformación elástica además de otros fenómenos de nanoplasticidad ${ }^{[12]}$.

Los valores de módulo elástico obtenidos en el ensayo de nanoindentación muestran cómo desciende el modulo elástico cuanto mayor es el contenido de niobio. Estos resultados van en concordancia con los obtenidos en el ensayo de flexión biaxial que relacionaban la fuerza y el desplazamiento en la parte elástica del ensayo. En la tabla IV se muestran todos

Tabla III. Tamaño de grano y microdureza de los materiales estudiados

Table III. Grain size and microhardness of the materials studied

\begin{tabular}{ccc}
\hline Aleación & $\begin{array}{c}\text { Microdureza } \\
(\mathbf{G P a})\end{array}$ & $\begin{array}{c}\text { Diámetro } \\
\text { medio de } \\
\text { grano }(\boldsymbol{\mu m})\end{array}$ \\
\hline $\mathrm{Ti}$ & $2,30 \pm 0,32$ & $108,72 \pm 23,12$ \\
$\mathrm{Ti}-20 \mathrm{Nb}$ & $2,87 \pm 0,21$ & $64,31 \pm 11,52$ \\
$\mathrm{Ti}-25 \mathrm{Nb}$ & $2,76 \pm 0,21$ & $51,44 \pm 8,88$ \\
$\mathrm{Ti}-30 \mathrm{Nb}$ & $2,82 \pm 0,32$ & $39,25 \pm 9,41$ \\
$\mathrm{Ti}-35 \mathrm{Nb}$ & $2,81 \pm 0,21$ & $29,20 \pm 12,21$ \\
$\mathrm{Ti}-40 \mathrm{Nb}$ & $2,59 \pm 0,29$ & $24,75 \pm 10,94$ \\
\hline
\end{tabular}

Tabla IV. Nanodureza y modulo elástico de las aleaciones de titanio tipo $\beta$ obtenidas con el ensayo de nanoindentación

Table IV. Nanohardness and Young's modulus of $\beta$-Ti alloys obtained by the nanoindentation test

\begin{tabular}{ccc}
\hline Aleación & $\begin{array}{c}\text { Módulo de } \\
\text { elasticidad (Gpa) }\end{array}$ & $\begin{array}{c}\text { Nanodureza } \\
\text { (Gpa) }\end{array}$ \\
\hline $\mathrm{Ti}-30 \mathrm{Nb}$ & $93,46 \pm 3,03$ & $3,47 \pm 0,41$ \\
$\mathrm{Ti}-35 \mathrm{Nb}$ & $89,73 \pm 6,67$ & $3,03 \pm 0,72$ \\
$\mathrm{Ti}-40 \mathrm{Nb}$ & $79,99 \pm 3,67$ & $3,02 \pm 0,38$ \\
\hline
\end{tabular}

los resultados, obtenidos mediante nanoindentación, de las aleaciones de titanio, tipo $\beta$.

Cabe destacar que existen muchas publicaciones ${ }^{[13}$ y 14$]$ relacionadas con el modulo elástico de las aleaciones tipo $\beta$. En general, se observan valores muy similares para las aleaciones $\mathrm{Ti}-\mathrm{Nb}$, a pesar de que algunas sean aleaciones obtenidas por forja y de que el valor de modulo elástico se haya obtenido por medio de ensayos por ultrasonidos o ensayos de compresión.

\section{CONCLUSIONES}

Se ha comprobado que mediante pulvimetalurgia convencional se pueden obtener aleaciones de titanio con altos contenidos de elemento aleante, de forma fácil y con alta tasa de repetitividad gracias a la gran capacidad de difusión del titanio. La mezcla elemental de polvos se ha mostrado como un proceso válido a la hora de obtener aleaciones, prácticamente, homogéneas en composición y, por tanto, en microestructura y en propiedades mecánicas ya que el titanio admite gran contenido de aleantes.

Las muestran obtenidas presentan poca porosidad y sufren grandes variaciones dimensionales en la etapa de sinterizado, debido a que la compactabilidad es baja. A pesar de todo esto, se obtienen valores de densidad relativa final muy próximos a los teóricos.

El ensayo de flexión biaxial es un ensayo válido para este tipo de materiales con altos porcentajes de elementos aleantes y para el tipo de muestras que se obtienen mediante pulvimetalurgia convencional. Se han obtenido valores altos de tensión máxima de rotura y la relación entre la fuerza y el desplazamiento muestra, de forma clara, la evolución de las propiedades elásticas de los materiales estudiados. 
La microdureza y la nanodureza experimentan la misma evolución descendente con el aumento del contenido de niobio, a pesar de la disminución del tamaño de grano, por lo que se puede afirmar que la influencia del niobio es mucho mayor que la del tamaño de grano.

La microestructura muestra como el valor de $25 \%$ en contenido de niobio es el valor límite entre aleaciones tipo $\alpha+\beta$ y aleaciones tipo $\beta$, para aleaciones pulvimetalúrgicas.

Por último y a pesar que el ensayo de nanoindentación no es el más apropiado para obtener el módulo elástico de este tipo de muestras debido a la porosidad, se han obtenido valores de módulo elástico ligeramente más altos que los encontrados en la literatura para las aleaciones tipo $\beta$.

\section{Agradecimientos}

Los autores agradecen al Ministerio de Ciencia e Innovación por la financiación de esta investigación a través del proyecto TRACE PET2008_0158_02.

\section{REFERENCIAS}

[1] H. Kawahara, Int. Dent. 33 (1983) 350-375.

[2] O.M. Ivasishin, D.G. Savvakin, V.S. Moxson,
K.A. Bondareval y F.H. Froes, Mater. Technol. 17 (2002) 45-51.

[3] V.S. Moxson y F.H. Froes, Int. J. Powder Metall. 37 (2001) 59-65.

[4] R. Godley, D. Starosvetsky e I. Gotman, J. Mater. Sci. Mater. Medicine 17 (2006) 63-67.

[5] G. He y M. Hagiwara, Mater. Sci. Eng. C 26 (2006) 14-19.

[6] D. Kuroda, M. Niinomi, M. Morinaga, Y. Kato y T. Yashiro, Mater. Sci. Eng. A 243 (1998) $244-$ 249.

[7] H.M. Silva, S.G. Schneider y C. Moura Neto, Mater. Sci. Eng. C 24 (2004) 679-682.

[8] R. Danzer, W. Harrer, P. Supancic, T. Lube, Z. Wang y A. Börger, J. Europ. Ceram. Soc. 27 (2007) 1.481-1.485.

[9] A. Börger, P. Supancic y R. Danzer, J. Europ. Ceram. Soc. 22 (2002) 1.425-1.436.

[10] T. Fett, G. Rizzi, E. Ernst, R. Müller y R. Oberacker, J. Europ. Ceram. Soc. 27 (2007) 1-12.

[11] ASM Materials Properties Handbook: Titanium Alloys, Ohio, EE. UU., 1994, pp. 165-260.

[12] D.J. Shuman, A.L.M. Costa y M.S. Andrade, Mater. Character. 58 (2007) 380-389.

[13] X. Li-Juan, X. Shu-Long, T. Jing, C. Yu-Yong y H. Yu-Dong, Trans. Nonferrrous Met. Soc. China 19 (2009) s639-s644.

[14] K. Han-Sol, K. Won-Yong y L. Sung-Hwan, Scr. Mater. 54 (2006) 887-891. 